\title{
Computational (DFT) simulations for comparative prediction of chemical reactivity and stability of linoleic and stearic acid molecules
}

\author{
Ituen, E. B. ${ }^{1,}$ ", Asuquo, J. E. ${ }^{1}$, Ogede, O. R. ${ }^{2}$ \\ ${ }^{1}$ Physical/Theoretical Chemistry Research Unit, Department of Chemistry, University of Uyo, Nigeria \\ ${ }^{2}$ Department of Science Technology, Federal Polytechnic, Ado-Ekiti, Nigeria \\ Email address: \\ ebituen@gmail.com (Ituen, E. B.)
}

\section{To cite this article:}

Ituen, E. B., Asuquo, J. E., Ogede, O. R.. Computational (DFT) Simulations for Comparative Prediction of Chemical Reactivity and Stability of Linoleic and Stearic Acid Molecules. International Journal of Computational and Theoretical Chemistry.

Vol. 2, No. 2, 2014, pp. 14-19. doi: 10.11648/j.ijctc.20140202.11

\begin{abstract}
The frontier molecular orbitals (HOMO and LUMO) of stearic and linoleic acids were simulated using density functional theory (DFT) at the B3LYP/6-31G*basis set level with the use of Spartan ' 10 wave function software with a view to comparing their reactivity and stability based on some theoretically calculated parameters. The total energy (absolute values), energy gap between the HOMO and LUMO, $\mathrm{E}_{\text {HOMO, }}$, total energy and global hardness values of stearic acids were found to be higher than those of linoleic acid while values of $\mathrm{E}_{\mathrm{LUMO}}$, dipole moment and global softness calculated were higher for linoleic acid than stearic acid. Results show that linoleic acid would have higher reactivity and lower stability than stearic acid due to its relative softness. Spectroscopic investigation gives similar spectral positions with an additional infra-red vibrational frequency at around $3000 \mathrm{~cm}^{-1}$ for linoleic acid.
\end{abstract}

Keywords: Chemical Reactivity, DFT, Frontier Orbitals, Linoleic Acid, Stability, Stearic Acid

\section{Introduction}

Linoleic acid (LA) is an unsaturated omega-6 fatty acid with molecular formula $\mathrm{C}_{18} \mathrm{H}_{31} \mathrm{COOH}$. It is a colorless liquid at room temperature. In physiological literature, it has a lipid number of 18:2 cis, cis-9,12. Chemically, linoleic acid is a carboxylic acid with an 18-carbon chain and two cis double bonds; the first double bond is located at the sixth carbon from the methyl end, hence the name omega-6. Linoleic acid belongs to one of the two families of essential fatty acids. The body cannot synthesize linoleic acid from other food components. Stearic acid is a saturated fatty acid with an 18carbon chain and has the IUPAC name octadecanoic acid. It is a waxy solid having the chemical formula $\mathrm{CH}_{3}\left(\mathrm{CH}_{2}\right)_{16} \mathrm{CO}_{2} \mathrm{H}$. Salts or esters of stearic acid are called stearates [1]. Figure 1 shows the structure of stearic and linoleic acids while a summary of some physical properties of stearic and linoleic acids are shown in table 1 for easy distinction.<smiles>CCCCCCCCCCCCCCCCC(=O)O</smiles>

(i)

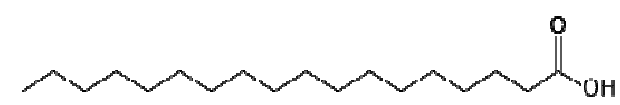

(ii)

Figure 1. Molecular structures of (i) linoleic acid (ii) stearic acid.

Table 1. Summary of some physical properties of stearic acid and linoleic acid.

\begin{tabular}{lll}
\hline Properties & Stearic acid & Linoleic acid \\
\hline Molecular mass $(\mathrm{g} / \mathrm{mol})$ & 284.48 & 280.45 \\
Appearance & White solid & Colourless oil \\
Density & $0.847 \mathrm{~g} / \mathrm{L}$ at $343 \mathrm{~K}$ & $0.99 \mathrm{~g} / \mathrm{cm}^{3}$ \\
Melting point $(\mathrm{K})$ & 343 & $261-268$ \\
Boiling point $(\mathrm{K})$ & 652 & 503 \\
Solubility in water & $3.0 \mathrm{~g} / \mathrm{L}$ & $0.139 \mathrm{mg} / \mathrm{L}$ \\
\hline
\end{tabular}

\section{Computational Method}

Density functional theory (DFT) is a popular quantum mechanical calculation tool for probe into structures and reactivity of chemical molecules. In this study, DFT at the B3LYP/6-31G*basis set level is used to calculate the 
frontier molecular orbitals energies, optimized geometric structures, dipole moments, total energies, energy gaps, global hardness and softness, absorption and vibrational spectroscopic properties of stearic acid and linoleic acid. These parameters are calculated using Spartan '10 wavefunction software [10]. The calculated values were correlated with the reactivity and stability of the fatty acids and the results obtained were used as a basis for comparison.

\section{Results and Discussion}

\subsection{Dipole Moment}

An important parameter that helps in the understanding of interaction between atoms in the same or different molecules is the dipole moment. It is a measure of the net molecular polarity, which is the magnitude of charge $(/ \mathrm{Q} /)$ at the either ends of the molecular dipole time the distance between the charges (equation 1). Dipole moment increases with increase in electronegativity of atoms [8]. Chemical reactivity usually increases with increase in dipole moment. The use of dipole moment to probe chemical reactivity according to our theoretical study suggests that linoleic acid ( $\mu=1.78$ Debye) would be more reactive than stearic acid ( $\mu=1.26$ Debye), which would imply that stearic acid would be more stable than linoleic acid.

$$
\mu=/ \mathrm{Q} / \mathrm{r}
$$

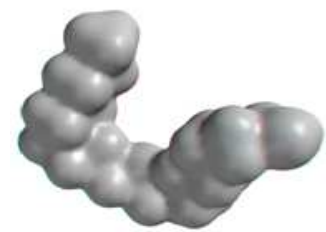

(i)

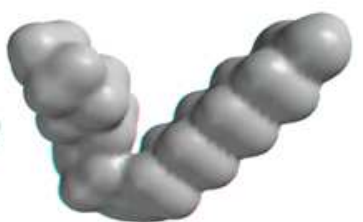

(ii)
Figure 2. The density of (i) stearic acid and (ii) linoleic acid using DFT at the B3LYP/6-31G*basis set level.

\subsection{Total Energy}

The minimum value of the total energy functional is the ground state energy of a system [3]. The electronic charge density which yields this minimum is then the exact single particle ground state energy. This makes the total energy calculated by quantum mechanical method a beneficial parameter. The total energy determines the occurrence or non-occurrence of chemical reactions and stereospecific paths in intra- and intermolecular processes. The total energy of a system is composed of the internal, potential, and kinetic energy. Hohenberg and Kohn [4] proved that the total energy of a system including that of the many body effects of electrons (exchange and correlation) in the presence of static external potential (for example, the atomic nuclei) is a unique functional of the charge density. Figure 2 shows the density of stearic acid and palmitic acid From our study, the total energy (absolute values) calculated using DFT at the B3LYP/6-31G*basis set level for stearic acid is higher than that of oleic acid (see table 2).

\subsection{HOMO-LUMO Energy Gap}

It is common knowledge that similar to the way electrons occupy the atomic orbitals, electrons occupy the molecular orbitals surrounding the molecule. The formations of molecular orbitals are from the linear combination of atomic orbitals or more specific, from the wave interaction of atomic orbitals. The study of energies of pairs of frontier orbitals, namely HOMO and LUMO of molecules provide reliable and quantitative data for straightforward prediction and comparative study of stabilities of molecules both from chemical and thermodynamic viewpoints. It has been reported earlier that HOMO-LUMO energy gap $(\Delta \mathrm{E})$ is an important stability index [2]. A large energy gap implies higher stability and lower chemical reactivity and vice versa. From the calculations made using DFT at the B $3 \mathrm{LYP} / 6-31 \mathrm{G}^{*}$ basis set level, $\mathrm{E}_{\mathrm{HOMO}}$ of stearic acid $(-7.47 \mathrm{eV})$ is greater than that of linoleic acid $(-6.30 \mathrm{eV})$. Also, the $\mathrm{E}_{\mathrm{LUMO}}$ of stearic acid (0.29 $\mathrm{eV})$ is less than that of linoleic acid $(0.24 \mathrm{eV})$. This suggests than linoleic acid would be of higher reactivity than stearic acid. The higher reactivity of linoleic acid would indicate a lower stability relative to stearic acid.

It could further be seen from the calculated amount of $\Delta \mathrm{E}$ values (table 2) that stearic acid has higher band gap energy than oleic acid. Thermodynamically, a lower energy is representative of higher stability of molecules and low reactivity. However, a molecule may be thermodynamically stable but kinetically unstable. Therefore, the proposed higher stability of stearic acid may be ascribed to kinetic stability due to saturation of the hydrophobic moiety compared to the unsaturation of that of linoleic acid. The two double bonds at positions 9 and 12 from the hydrophobic component in addition to the hydrophilic carboxylic group of linoleic acid would probably convey enhanced reactivity on the molecule. An experimental verification would probably help to provide more explanations these discrepancies.

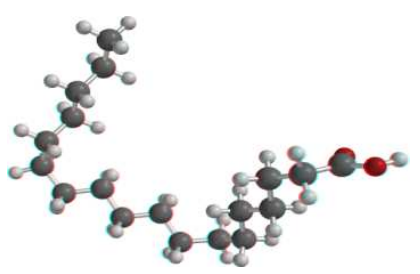

(i)

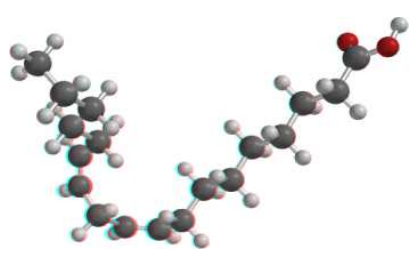

(ii)

Figure 3. Optimized structure of (i) stearic acid and (ii) linoleic acid using DFT at the B3LYP/6-31G*basis set level. 


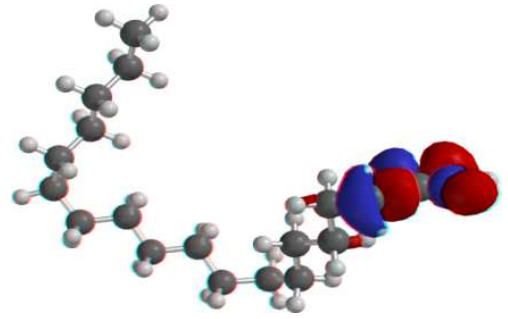

(i)

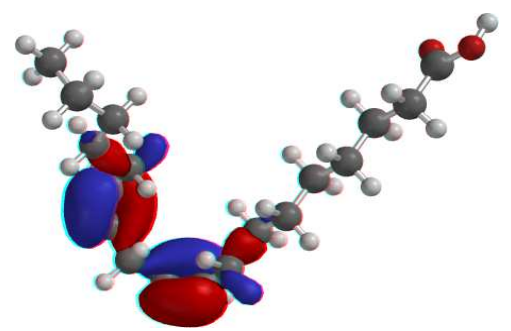

(ii)

Figure 4. The highest occupied molecular orbital (HOMO) density of (i) stearic acid and (ii) linoleic acid using DFT at the B3LYP/6-31G*basis set level.

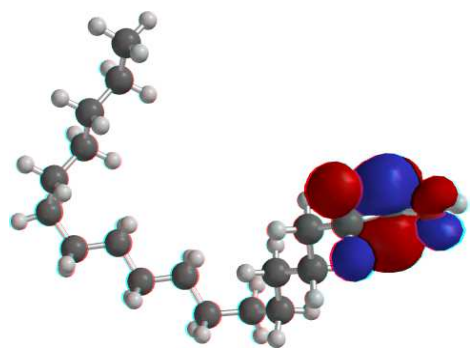

(i)

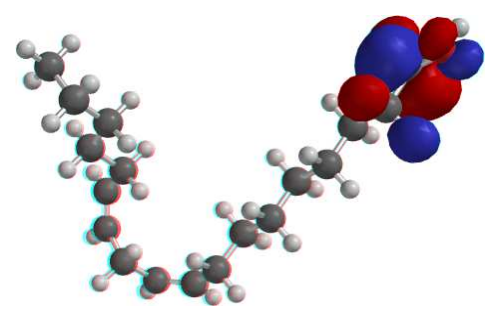

(ii)

\subsection{Global Hardness and Global Softness}

On the basis of the assumptions of the HSAB principle of Pearson, [5], within the framework of density functional theory, chemical reactivity and stability of a molecule may be associated with its global hardness $(\alpha)$ and global softness $(\beta)$ calculated according to equation 2 and 3 . Increase in hardness increases movement of the system towards a more stable configuration-equilibrium configuration. When a molecule moves away from its equilibrium configuration its hardness value decreases. Greater hardness therefore implies high stability and low reactivity. Global softness has an inverse relationship with hardness: soft molecules undergo changes in electron density more easily than the hard molecules and are more reactive than the hard molecules [7]. Values of global hardness and global softness calculated for stearic acid and linoleic acid show that stearic acid would be harder than linoleic acid. In other words, linoleic acid would be a softer molecule than stearic acid. This is in agreement with the higher reactivity and lower stability earlier predcted for linoleic acid than stearic acid.

$$
\begin{aligned}
& \alpha=\Delta E / 2 \\
& \beta=1 / \alpha
\end{aligned}
$$

Tables 2. Some molecular properties of stearic acid and linoleic acid calculated using DFT at the B3LYP/6-31G* basis set level.

\begin{tabular}{lll}
\hline Parameter & Stearic acid & linoleic acid \\
\hline EHOMO (eV) & -7.47 & -6.30 \\
ELUMO (eV) & 0.29 & 0.33 \\
$\Delta \mathrm{E}(\mathrm{eV})$ & 7.76 & 6.63 \\
Total energy & -23348.69 & -23281.75 \\
Dipole moment (Debye) & 1.26 & 1.78 \\
Global hardness & 3.88 & 3.31 \\
Global softness & 0.2577 & 0.3021 \\
\hline
\end{tabular}

Figure 5. The Lowest unoccupied molecular orbital (LUMO) density of (i) stearic acid and (ii) linoleic acid using DFT at the B3LYP/6-31G*basis set level.

Table 3 (a). Mullikan charge distribution of stearic acid calculated using DFT at the B3LYP/6-31G* basis set level.

\begin{tabular}{lllllllllll}
\hline ATOM & C1 & O1 & O2 & H2 & C2 & H1 & H4 & C3 & H5 & H6 \\
\hline CHARGE & +0.579 & -0.464 & -0.569 & +0.407 & -0.354 & +0.171 & +0.177 & -0.252 & +0.154 & +0.130 \\
ATOM & C4 & H3 & H7 & C5 & H9 & H10 & C6 & H8 & H11 & C7 \\
CHARGE & -0.262 & +0.122 & +0.152 & -0.254 & +0.133 & +0.132 & -0.255 & +0.125 & +0.129 & -0.260 \\
ATOM & H12 & H13 & C 8 & H14 & H15 & C9 & H16 & H18 & C10 & H17 \\
CHARGE & +0.128 & +0.128 & -0.253 & +0.125 & +0.127 & -0.259 & +0.135 & +0.127 & -0.254 & +0.125 \\
ATOM & H19 & C11 & H20 & H22 & C12 & H21 & H23 & C13 & H25 & H26 \\
CHARGE & +0.126 & -0.253 & +0.133 & +0.127 & -0.255 & +0.126 & +0.126 & -0.260 & +0.128 & +0.128 \\
ATOM & $\mathrm{C} 14$ & $\mathrm{H} 24$ & $\mathrm{H} 27$ & $\mathrm{C} 15$ & $\mathrm{H} 29$ & $\mathrm{H} 30$ & $\mathrm{C} 16$ & $\mathrm{H} 28$ & $\mathrm{H} 31$ & $\mathrm{C} 17$ \\
CHARGE & -0.254 & +0.127 & +0.127 & -0.260 & +0.126 & +0.137 & -0.246 & +0.125 & +0.125 & -0.247 \\
ATOM & $\mathrm{H} 32$ & $\mathrm{H} 34$ & $\mathrm{C} 18$ & $\mathrm{H} 33$ & $\mathrm{H} 35$ & $\mathrm{H} 36$ & & & & \\
CHARGE & +0.130 & +0.130 & -0.441 & +0.140 & +0.141 & +0.141 & & & & \\
\hline
\end{tabular}


Table 3 (b). Mullikan charge distribution of linoleic acid calculated using DFT at the B3LYP/6-31G* basis set level.

\begin{tabular}{|c|c|c|c|c|c|c|c|c|c|c|c|}
\hline АТОМ & $\mathrm{C} 1$ & 01 & $\mathbf{O 2}$ & H2 & $\mathrm{C} 2$ & H1 & H4 & $\mathrm{C} 3$ & H3 & H5 & $\mathrm{C4}$ \\
\hline CHARGE & +0.577 & -0.462 & -0.572 & +0.407 & -0.355 & +0.173 & +0.174 & -0.249 & +0.149 & +0.150 & -0.258 \\
\hline ATOM & H6 & $\mathrm{H} 8$ & $\mathrm{C} 5$ & $\mathrm{H} 7$ & H9 & C6 & $\mathrm{H} 10$ & $\mathrm{H} 12$ & $\mathrm{C} 7$ & H11 & H13 \\
\hline CHARGE & +0.128 & +0.128 & -0.254 & +0.131 & +0.131 & -0.254 & +0.127 & +0.127 & -0.253 & +0.130 & +0.142 \\
\hline ATOM & $\mathrm{C} 8$ & H14 & H16 & $\mathrm{C} 9$ & H17 & $\mathrm{C} 10$ & H15 & C11 & H18 & H19 & $\mathrm{C} 12$ \\
\hline CHARGE & -0.302 & +0.136 & +0.135 & -0.103 & +0.118 & -0.094 & +0.119 & -0.348 & +0.145 & +0.149 & -0.100 \\
\hline ATOM & $\mathrm{H} 21$ & $\mathrm{C} 13$ & H20 & $\mathrm{C} 14$ & $\mathrm{H} 22$ & $\mathrm{H} 23$ & $\mathrm{C} 15$ & $\mathrm{H} 24$ & H26 & $\mathrm{C} 16$ & $\mathrm{H} 25$ \\
\hline CHARGE & +0.119 & -0.097 & +0.117 & -0.304 & +0.139 & +0.136 & $-0,253$ & +0.135 & +0.134 & -0.249 & +0.126 \\
\hline ATOM & $\mathrm{H} 27$ & $\mathrm{C} 17$ & $\mathrm{H} 29$ & $\mathrm{H} 30$ & $\mathrm{C} 18$ & $\mathrm{H} 28$ & H31 & H32 & & & \\
\hline CHARGE & +0.126 & -0.248 & +0.130 & +0.130 & -0.433 & +0.140 & +0.142 & +0.147 & & & \\
\hline
\end{tabular}

Table 4 (a). Bond order of stearic acid calculated using DFT at the B3LYP/6-31G* basis set level.

\begin{tabular}{|c|c|c|c|c|c|c|c|c|c|c|}
\hline BOND ORDER & C101 & $\mathrm{C} 102$ & $\mathrm{C1C2}$ & 0102 & O1H2 & O2H2 & C2H1 & $\mathrm{C2H4}$ & $\mathrm{C2C3}$ & C3H5 \\
\hline MULLIKAN & 1.866 & 1.069 & 0.968 & 0.065 & 0.037 & 0.760 & 0.921 & 0.920 & 0.993 & 0.931 \\
\hline BOND ORDER & $\mathrm{C} 3 \mathrm{H} 6$ & $\mathrm{C} 3 \mathrm{C} 4$ & $\mathrm{C} 4 \mathrm{H} 3$ & $\mathrm{C} 4 \mathrm{H} 7$ & $\mathrm{C} 4 \mathrm{C} 5$ & $\mathrm{C} 5 \mathrm{H} 9$ & $\mathrm{C} 5 \mathrm{H} 10$ & $\mathrm{C} 5 \mathrm{C} 6$ & $\mathrm{C} 6 \mathrm{H} 8$ & C6H11 \\
\hline MULLIKAN & 0.936 & 1.010 & 0.938 & 0.929 & 1.007 & 0.929 & 0.932 & 1.011 & 0.938 & 0.939 \\
\hline BOND ORDER & $\mathrm{C} 6 \mathrm{C} 7$ & C7H12 & C7H13 & $\mathrm{C} 7 \mathrm{C} 8$ & $\mathrm{C} 8 \mathrm{H} 14$ & $\mathrm{C} 8 \mathrm{H} 15$ & $\mathrm{C} 8 \mathrm{C} 9$ & С9H16 & С9H18 & $\mathrm{C} 9 \mathrm{C} 10$ \\
\hline MULLIKAN & 1.014 & 0.942 & 0.938 & 0.995 & 0.939 & 0.942 & 1.012 & 0.930 & 0.938 & 1.005 \\
\hline BOND ORDER & $\mathrm{C} 10 \mathrm{H} 17$ & $\mathrm{C} 10 \mathrm{H} 19$ & $\mathrm{C} 10 \mathrm{C} 11$ & $\mathrm{C} 11 \mathrm{H} 20$ & $\mathrm{C} 11 \mathrm{H} 22$ & $\mathrm{C} 11 \mathrm{C} 12$ & $\mathrm{C} 12 \mathrm{H} 21$ & $\mathrm{C} 12 \mathrm{H} 23$ & $\mathrm{C} 12 \mathrm{C} 13$ & $\mathrm{C} 13 \mathrm{H} 25$ \\
\hline MULLIKAN & 0.939 & 0.938 & 1.003 & 0.933 & 0.938 & 1.011 & 0.938 & 0.939 & 1.014 & 0.943 \\
\hline BOND ORDER & $\mathrm{C} 13 \mathrm{H} 26$ & $\mathrm{C} 13 \mathrm{C} 14$ & $\mathrm{C} 14 \mathrm{H} 24$ & $\mathrm{C} 14 \mathrm{H} 27$ & $\mathrm{C} 14 \mathrm{C} 15$ & $\mathrm{C} 15 \mathrm{H} 29$ & $\mathrm{C} 15 \mathrm{H} 30$ & $\mathrm{C} 15 \mathrm{C} 16$ & $\mathrm{C} 16 \mathrm{H} 28$ & $\mathrm{C} 16 \mathrm{H} 31$ \\
\hline MULLIKAN & 0.939 & 0.989 & 0.939 & 0.943 & 1.011 & 0.938 & 0.932 & 1.007 & 0.939 & 0.933 \\
\hline BOND ORDER & $\mathrm{C} 16 \mathrm{C} 17$ & C17H32 & C17H34 & C17C18 & $\mathrm{C} 18 \mathrm{H} 33$ & $\mathrm{C} 18 \mathrm{H} 35$ & C18H36 & & & \\
\hline MULLIKAN & 1.011 & 0.942 & 0.943 & 1.016 & 0.953 & 0.952 & 0.952 & & & \\
\hline
\end{tabular}

Table 4 (b). Bond order of linoleic acid calculated using DFT at the B3LYP/6-31G* basis set level.

\begin{tabular}{|c|c|c|c|c|c|c|c|c|c|c|}
\hline BOND ORDER & C101 & $\mathrm{C} 102$ & $\mathrm{C1C2}$ & 0102 & O1H2 & $\mathrm{O} 2 \mathrm{H} 2$ & C2H1 & $\mathrm{C} 2 \mathrm{H} 4$ & $\mathrm{C2C3}$ & $\mathrm{C} 3 \mathrm{H} 5$ \\
\hline MULLIKAN & 1.866 & 1.069 & 0.968 & 0.065 & 0.037 & 0.760 & 0.921 & 0.920 & 0.993 & 0.931 \\
\hline BOND ORDER & $\mathrm{C} 3 \mathrm{H} 6$ & $\mathrm{C} 3 \mathrm{C} 4$ & $\mathrm{C} 4 \mathrm{H} 3$ & $\mathrm{C} 4 \mathrm{H} 7$ & $\mathrm{C} 4 \mathrm{C} 5$ & $\mathrm{C} 5 \mathrm{H} 9$ & $\mathrm{C} 5 \mathrm{H} 10$ & $\mathrm{C} 5 \mathrm{C} 6$ & $\mathrm{C} 6 \mathrm{H} 8$ & C6H11 \\
\hline MULLIKAN & 0.936 & 1.010 & 0.938 & 0.929 & 1.007 & 0.929 & 0.932 & 1.011 & 0.938 & 0.939 \\
\hline BOND ORDER & $\mathrm{C} 6 \mathrm{C} 7$ & $\mathrm{C} 7 \mathrm{H} 12$ & $\mathrm{C} 7 \mathrm{H} 13$ & $\mathrm{C} 7 \mathrm{C} 8$ & $\mathrm{C} 8 \mathrm{H} 14$ & $\mathrm{C} 8 \mathrm{H} 15$ & $\mathrm{C} 8 \mathrm{C} 9$ & С9H16 & С9H18 & $\mathrm{C} 9 \mathrm{C} 10$ \\
\hline MULLIKAN & 1.014 & 0.942 & 0.938 & 0.995 & 0.939 & 0.942 & 1.012 & 0.930 & 0.938 & 1.005 \\
\hline BOND ORDER & $\mathrm{C} 10 \mathrm{H} 17$ & $\mathrm{C} 10 \mathrm{H} 19$ & $\mathrm{C} 10 \mathrm{C} 11$ & $\mathrm{C} 11 \mathrm{H} 20$ & $\mathrm{C} 11 \mathrm{H} 22$ & $\mathrm{C} 11 \mathrm{C} 12$ & $\mathrm{C} 12 \mathrm{H} 21$ & $\mathrm{C} 12 \mathrm{H} 23$ & $\mathrm{C} 12 \mathrm{C} 13$ & $\mathrm{C} 13 \mathrm{H} 25$ \\
\hline MULLIKAN & 0.939 & 0.938 & 1.003 & 0.933 & 0.938 & 1.011 & 0.938 & 0.939 & 1.014 & 0.943 \\
\hline BOND ORDER & $\mathrm{C} 13 \mathrm{H} 26$ & $\mathrm{C} 13 \mathrm{C} 14$ & $\mathrm{C} 14 \mathrm{H} 24$ & $\mathrm{C} 14 \mathrm{H} 27$ & $\mathrm{C} 14 \mathrm{C} 15$ & $\mathrm{C} 15 \mathrm{H} 29$ & $\mathrm{C} 15 \mathrm{H} 30$ & $\mathrm{C} 15 \mathrm{C} 16$ & $\mathrm{C} 16 \mathrm{H} 28$ & $\mathrm{C} 16 \mathrm{H} 31$ \\
\hline MULLIKAN & 0.939 & 0.989 & 0.939 & 0.943 & 1.011 & 0.938 & 0.932 & 1.007 & 0.939 & 0.933 \\
\hline BOND ORDER & $\mathrm{C} 16 \mathrm{C} 17$ & $\mathrm{C} 17 \mathrm{H} 32$ & $\mathrm{C} 17 \mathrm{H} 34$ & $\mathrm{C} 17 \mathrm{C} 18$ & $\mathrm{C} 18 \mathrm{H} 33$ & $\mathrm{C} 18 \mathrm{H} 35$ & $\mathrm{C} 18 \mathrm{H} 36$ & & & \\
\hline MULLIKAN & 1.011 & 0.942 & 0.943 & 1.016 & 0.953 & 0.952 & 0.952 & & & \\
\hline
\end{tabular}

\subsection{Spectroscopic Investigation}

Results obtained from theoretical calculation of electronic absorption wavelength and vibrational frequencies of stearic acid and linoleic acids are shown in figures 5-8. From the above figures, it may be inferred that the spectroscopic characteristics of linoleic acid and stearic acid are dissimilar. The fingerprint region of infra-red spectrum of linoleic acid showed sharp and intense peaks than stearic acid. The prominent intense peak for linoleic acid at around $1400 \mathrm{~cm}^{-1}$ may be assigned to the cis $\mathrm{C}=\mathrm{C}$ twin functionality present in its molecular structure. This peak may also be used to justify the higher reactivity of linoleic acid over stearic acid. The peaks at about 1700$1800 \mathrm{~cm}^{-1}$ may be assigned to the carbonyl present in the hydrophilic carboxylic acid ends of both molecules. On the other hand, the ultraviolet spectra of the fatty acids show only very slight differences in their absorption wavelengths. 


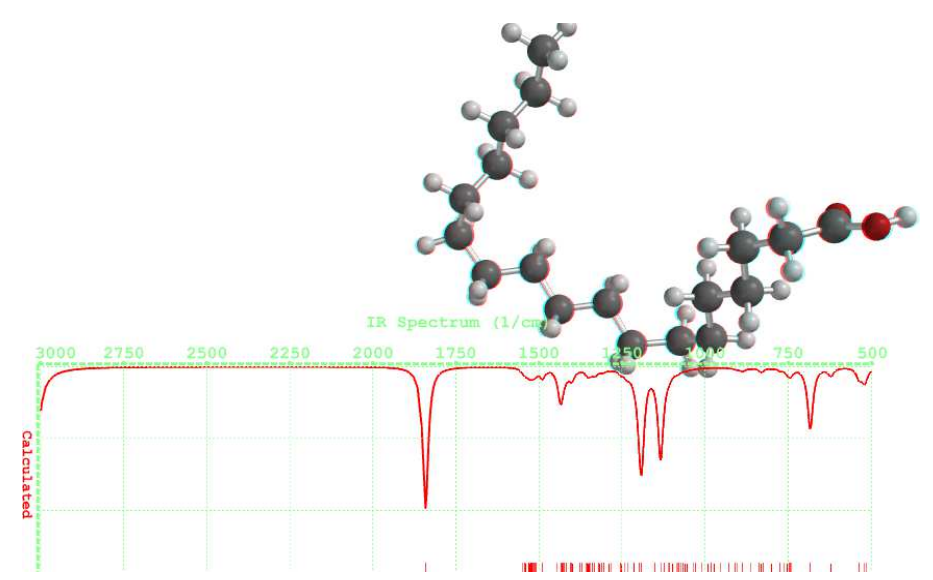

(i)

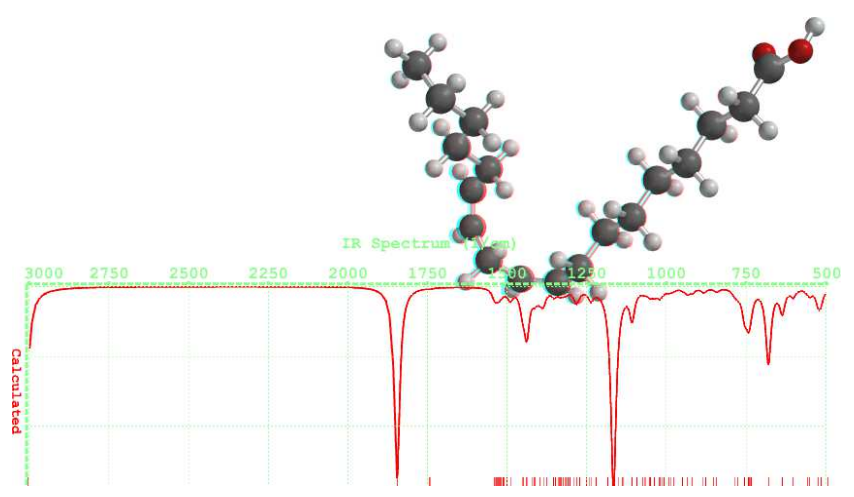

(ii)

Figure 6. Infra-red spectra of (i) stearic acid and (ii) linoleic acid using DFT at the B3LYP/6-31G* basis set level.

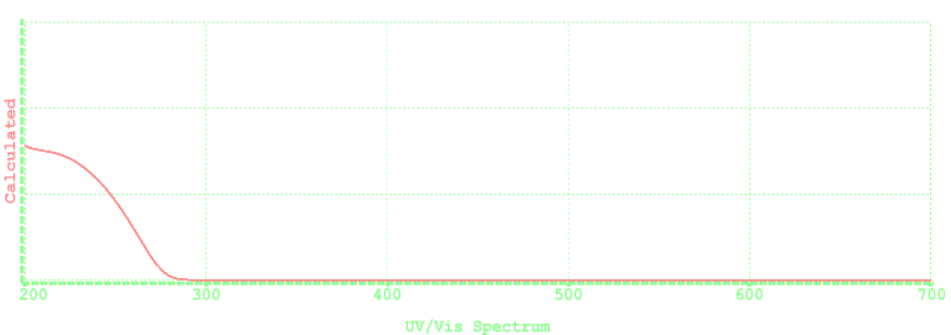

(i)

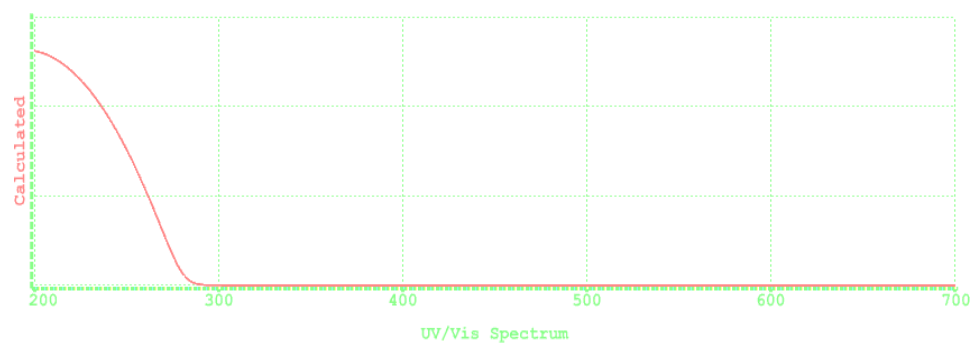

(ii)

Figure 7. Ultra-violet spectra of (i) stearic acid and (ii) linoleic acid using DFT at the B3LYP/6-31G* basis set level.

\section{Conclusions}

On the basis of this study, it has been concluded that linoleic acid would show higher chemical reactivity than stearic acid judged from the values of their band gap energy differences, total energies, dipole moments, global hardness and softness values and spectral bands and peaks. It has also been concluded that linoleic acid is a soft molecule compared to stearic acid. Our study has also shown that stearic acid would be more stable than oleic acid. However, experimental verification would be needed to further ascertain adherence to these predictions. 


\section{References}

[1] Gunstone, F. D., John L. Harwood, and Albert J. Dijkstra. Boca Raton: CRC Press, 2007. ISBN 0849396883 | ISBN 978-0849396885

[2] "The Inheritance of High Oleic Acid in Peanut". The J Hered. 80,3(1989) 252

[3] Faust, W. L. Science. 245 (1989) 37.

[4] Fukui, K. Science.218 (1982) 747.
[5] Pearson, R. G. J. Chem. Phys. 52(1970) 2167, 53 (1970) 2986.

[6] Pearson, R. G. J. Am. Chem. Soc. 91(1969) 1252, 4947.

[7] Pearson, R. G., J. Am. Chem. Soc. 85 (1963)353; Science. 151 (1966) 172.

[8] I. B. Obot and A. S. Johnson. Comput. Chem. 43 (2012) 6658 .

[9] N. O. Obi-Egbedi, I. B. Obot, M. I. El-khaiary. J. Mol. Struct. 1002 (2011) 86.

[10] Spartan '10 Wavefunction, Inc. Irvine, C.A. 